\title{
Anandamide, Acting via CB2 Receptors, Alleviates LPS-Induced Neuroinflammation in Rat Primary Microglial Cultures
}

\author{
Natalia Malek, ${ }^{1,2}$ Katarzyna Popiolek-Barczyk, ${ }^{2}$ Joanna Mika, $^{2}$ \\ Barbara Przewlocka, ${ }^{2}$ and Katarzyna Starowicz ${ }^{1,2}$ \\ ${ }^{1}$ Laboratory of Pain Pathophysiology, Institute of Pharmacology, Polish Academy of Sciences, Smetna 12 Street, 31-343 Krakow, Poland \\ ${ }^{2}$ Department of Pain Pharmacology, Institute of Pharmacology, Polish Academy of Sciences, Smetna 12 Street, 31-343 Krakow, Poland
}

Correspondence should be addressed to Katarzyna Starowicz; starow@if-pan.krakow.pl

Received 27 February 2015; Accepted 27 March 2015

Academic Editor: Giovanni Cirillo

Copyright (C) 2015 Natalia Malek et al. This is an open access article distributed under the Creative Commons Attribution License, which permits unrestricted use, distribution, and reproduction in any medium, provided the original work is properly cited.

Microglial activation is a polarized process divided into potentially neuroprotective phenotype M2 and neurotoxic phenotype M1, predominant during chronic neuroinflammation. Endocannabinoid system provides an attractive target to control the balance between microglial phenotypes. Anandamide as an immune modulator in the central nervous system acts via not only cannabinoid receptors (CB1 and CB2) but also other targets (e.g., GPR18/GPR55). We studied the effect of anandamide on lipopolysaccharideinduced changes in rat primary microglial cultures. Microglial activation was assessed based on nitric oxide (NO) production. Analysis of mRNA was conducted for M1 and M2 phenotype markers possibly affected by the treatment. Our results showed that lipopolysaccharide-induced NO release in microglia was significantly attenuated, with concomitant downregulation of M1 phenotypic markers, after pretreatment with anandamide. This effect was not sensitive to CB1 or GPR18/GPR55 antagonism. Administration of CB2 antagonist partially abolished the effects of anandamide on microglia. Interestingly, administration of a GPR18/GPR55 antagonist by itself suppressed NO release. In summary, we showed that the endocannabinoid system plays a crucial role in the management of neuroinflammation by dampening the activation of an M1 phenotype. This effect was primarily controlled by the CB2 receptor, although functional cross talk with GPR18/GPR55 may occur.

\section{Introduction}

Neurodegenerative disorders, such as Alzheimer's disease, Parkinson's disease, multiple sclerosis, stroke, and chronic pain, are associated with ongoing inflammation in the central nervous system (CNS) [1-6]. One of the striking hallmarks of these neurodegenerative disorders is chronic microglial activation. Microglial cells are of monocytic origin and play the role of the resident phagocytes of the innate immune system in the CNS. However, there is a lack of information about the initial signals that trigger microglial activation; neuronal depolarization, extracellular ion changes, nitric oxide (NO), and proinflammatory cytokines may contribute to microglial reactivity [7-9]. In our study, the activation of microglia was induced by lipopolysaccharide (LPS), a widely described agonist of toll-like receptor-4 (TLR-4) that is responsible for stimulation of the immune system [10].
Recent studies have shown that activated microglia can be divided into two phenotypic profiles. The classical M1 state, characterized by proinflammatory factors for example, interleukins (IL-1B, IL-18, and IL-6) and inducible nitric oxide synthase (NOS2) [11-14], is neurotoxic and therefore contributes to secondary neuronal damage, cell death, and demyelination, which lead to neurodegeneration $[15,16]$. The neuroprotective M2 state, known as "alternative activation," is associated with the release of anti-inflammatory factors, such as IL-10, IL-4, and NGF $[13,17,18]$. There is a paucity of information about the regulation of microglial polarization. Several studies indicate that the endocannabinoid system provides an attractive target for managing microglial-derived neuroinflammation and may regulate many aspects of the brain's inflammatory response, including the release of M1 phenotype specific cytokines [19]. The endocannabinoid system modulates both neuronal and immune functions 
TABLE 1: Compounds interacting with the endocannabinoid system used in the study.

\begin{tabular}{lcccc}
\hline Compound & Description & Used concentration & Vehicle & Producer, cat number \\
\hline AEA & Endocannabinoid & $1-2 \mu \mathrm{M}$ & $10 \%$ EtOH & Tocris, \#1339 \\
AM-251 & CB1 antagonist & $0.1-0.5 \mu \mathrm{M}$ & $2 \% \mathrm{DMSO}$ & Tocris, \#1117 \\
AM-630 & CB2 antagonist & $0.1-0.5 \mu \mathrm{M}$ & $2 \% \mathrm{DMSO}$ & Tocris, \#1120 \\
CID-16020046 & GPR18/55 antagonist & $0.1-0.5 \mu \mathrm{M}$ & $2 \% \mathrm{DMSO}$ & Tocris, \#4959 \\
\hline
\end{tabular}

through two protein-coupled cannabinoid receptors (CB1 and CB2), although endocannabinoids, especially anandamide (AEA), can activate numerous other receptors like PPARS, TRPV1, and GPR18/GPR55 [20]. The latter, involved in immunological responses, represents an interesting molecular target for the control of neuroinflammation [21-23]. Both cannabinoid receptors are expressed in microglia and may act as immune modulators in the CNS [24, 25]. Moreover, it has been proposed that microglia are the main population of cells responsible for the production of AEA in the CNS, as primary microglial cultures produce approximately 20 -fold more of this compound than neuronal or astrocyte cultures [26]. Therefore, it is important to investigate the effect of AEA on microglia, especially during activation, as studies by Liu et al. [27] have shown increased production of AEA in macrophages after LPS induction.

Many of the neurodegenerative conditions of the CNS result in increased levels of endogenous AEA [28-30]; therefore, the endocannabinoid system may provide an attractive target to influence microglial phenotype during chronic inflammation. Therefore, to increase our understanding of the role of the endocannabinoid system in the modulation of microglial polarization, we explored the possible therapeutic action of AEA and AM-251, AM-630, and CID-16020046 at cannabinoid and GPR18/GPR55 receptors in the in vitro model of LPS-induced microglial activation.

\section{Materials and Methods}

2.1. Microglial Cell Cultures and Treatments. Primary cultures of microglial cells were prepared from 1-day-old Wistar rat pups as previously described [31, 32]. Briefly, cells were isolated from the rats' cerebral cortices and were plated at a density of $3 \times 10^{5}$ cells $/ \mathrm{cm}^{2}$ in a culture medium that consisted of DMEM/GlutaMAX/high glucose (Gibco, USA), supplemented with heat-inactivated $10 \%$ fetal bovine serum (Gibco, USA), $100 \mathrm{U} / \mathrm{mL}$ penicillin, and $0.1 \mathrm{mg} / \mathrm{mL}$ streptomycin (Gibco, USA). Cells were placed on poly-Llysine-coated $75-\mathrm{cm}^{2}$ culture flasks and were maintained at $37^{\circ} \mathrm{C}$ and $5 \% \mathrm{CO}_{2}$. The culture medium was changed after 4 days. The loosely adherent microglial cells were recovered after 9 days by mild shaking and centrifugation. Microglial cells were suspended in a culture medium and plated at a final density of $2 \times 10^{5}$ cells onto 24 -well plates and $4 \times 10^{4}$ cells onto 96-well plates. Adherent cells were incubated for $48 \mathrm{~h}$ in culture medium before being used for the analyses. Cell specificity was determined using an antibody to OX-42 (a microglial marker) in cultures of primary microglia. Levels of $\mathrm{Clq}$ (a microglial marker) and
Gfap (an astroglial marker) mRNA were also investigated. Cultured primary microglia were more than $97 \%$ positive for OX-42 and C1q. Primary microglial cell cultures were treated with compounds (Table 1) for $15 \mathrm{~min}$ each and then for $24 \mathrm{~h}$ with LPS (100 ng/mL) (lipopolysaccharide from Escherichia coli 0111:B4; Sigma-Aldrich, USA) for mRNA analysis. In the case of coadministration of AM-251, AM-630, and CID16020046 with AEA, antagonists were administered $15 \mathrm{~min}$ before AEA.

2.2. Griess Assay. The Griess method was used to quantify aqueous nitrite concentrations. The Griess method involves a colorimetric measurement of the concentration of nitrite ions $\left(\mathrm{NO}_{2}{ }^{-}\right)$, which are a stable, nonvolatile breakdown product of NO. Medium collected from above the tested cells $(50 \mathrm{~mL})$ was transferred to 96 -well plates in triplicate. Griess A reagent was added ( $1 \%$ sulfanilamide in $5 \%$ phosphoric acid) to the medium, and after $10 \mathrm{~min}$ incubation at room temperature, Griess B reagent was added (0.1\%, dihydrochloride N-(1naphthyl)-ethylenediamine). The absorbance of samples was read at $\lambda=540 \mathrm{~nm}$. The results are presented as a percentage of released nitric oxide relative to the positive control (cells treated with LPS).

2.3. LDH Assay. Compound cytotoxicity was measured using a Lactate Dehydrogenase (LDH) Cytotoxicity Detection Kit (Roche, Basel, Switzerland). LDH is a stable cytoplasmic enzyme present in all cells, which is released to the cell medium during plasma membrane damage. Medium from cells was collected $24 \mathrm{~h}$ after LPS stimulation and placed in 96-well plates. Tetrazolium salt was then added for $30 \mathrm{~min}$. Sample absorbance was measured at a wavelength of $\lambda=$ $492 \mathrm{~nm}$ using a spectrophotometer (LabSystems Multiskan, LabX, Canada). The results were expressed as a percentage of the absorbance in negative control cells (cells not treated with LPS or other compounds).

2.4. RNA Preparation and Quantitative Real-Time PCR. Cell samples were collected in Trizol Reagent (Invitrogen, Carlsbad, CA, USA) and homogenized by pipetting and vortexing. RNA was isolated according to Chomczynski's method [33]. The total RNA concentration was measured using a NanoDrop ND-1000 Spectrometer (Nano-Drop Technologies, Wilmington, DE, USA). Reverse transcription of total RNA (500 ng per sample) was performed using iScript reverse transcriptase (Bio-Rad, Hercules, CA, USA), according to the manufacturer's protocol. qPCR reactions were performed using Assay-on-Demand TaqMan probes and TaqMan Universal PCR Master Mix (Applied Biosystems, 


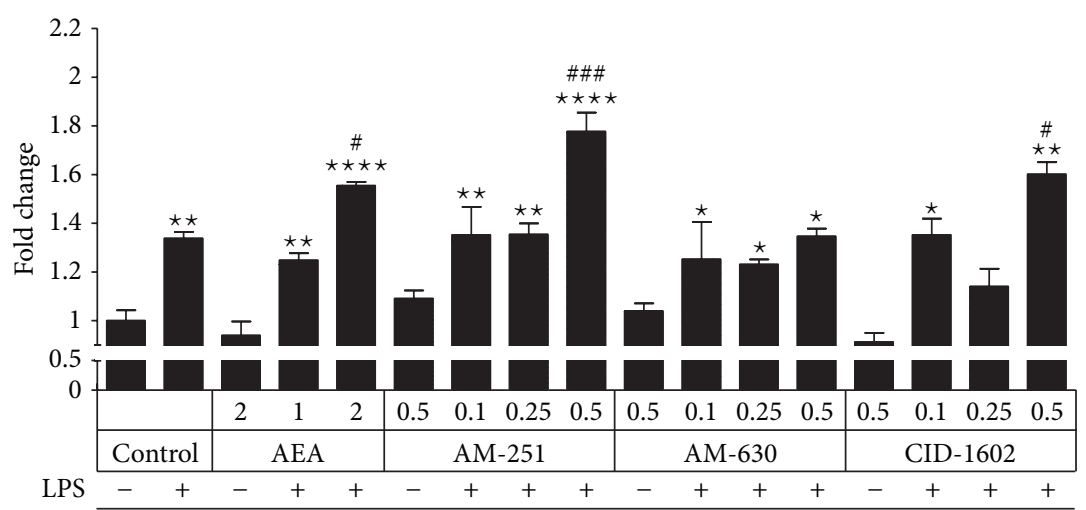

FIGURE 1: Compound cytotoxicity determined using the LDH assay. The test was performed 24 hours after LPS stimulation. The data are presented as the mean \pm SEM and represent the normalized averages derived from 10 to 15 samples per group. The results are presented as fold-change relative to the unstimulated control. Statistical analysis was performed using one-way ANOVA followed by Bonferroni post hoc tests. Statistical $P$ values $<0.05$ were considered significant. ${ }^{*}$ It denotes a significant difference versus the nonstimulated control; \#, versus the LPS-stimulated control.

Foster, CA, USA), according to the manufacturer's protocol. The following probes were used: Rn01527840_ml (Hprt1), Rn02758689_s1 (Cb1), Rn04342831_s1 (Cb2), Rn04244746_m1 (C1q), Rn00566603_m1 (Gfap), Rn00561420_m1 (Il-6), Rn01483828_m1 (Cox2), Rn00580432_ml (Illb), Rn00587615_ ml (Il-13), Rn01422083_ml (Il-18), Rn01456866_ml (Il-4), Rn00563409_m1 (Il-10), Rn03037213_s1 (Gpr55), Rn01493247_ m1 (Gpr18), Rn01533872 (Ngf), Rn00561646_ml (Nos2), and Rn01525859 (Tnf). Reactions were run on a Real-Time PCR iCycler IQ (Bio-Rad, Hercules, CA, USA) with version 3.0 of the software. Cycle threshold values $(\mathrm{Ct})$ were calculated automatically. Expression of the Hprt1 (hypoxanthine phosphoribosyltransferase 1) transcript was quantified to control for variation in cDNA amounts. The abundance of RNA was calculated as $2^{\text {(-normalized threshold cycle) }}$.

2.5. Statistical Analyses. The experimental data were obtained for experimental groups as follows: $n=4-6$ for the analysis of the expression of receptors and inflammatory factors at the mRNA level and $n=10-15$ for the Griess and LDH biochemical tests. All data are presented as the mean \pm S.E.M. The results are presented as a \% of expressing cells for glial markers, as a fold-change relative to the negative control for mRNA expression and LDH results, and as a \% of the negative control for the assay of released nitrogen oxide (Griess test). The results were statistically analyzed using GraphPad Prism 5 (Version 5.0.4, GraphPad Software), which was used to perform a one-way analysis of variance ANOVA and Bonferroni post hoc test on the results. Differences with $P<0.05$ were considered statistically significant. Charts were prepared using GraphPad Prism v.5.04 (GraphPad Software, USA). The graphs indicate statistical significance according to the scheme:,$+ P<0.05 ;++, P<0.01 ;+++$, $P<0.001$; and,$++++ P<0.0001$, where ${ }^{*}$ indicates a significant difference compared to the nonstimulated control, \# indicates a significant difference compared to the LPSstimulated control, and \$ indicates a significant difference compared to the LPS-stimulated cells treated with AEA.

\section{Results}

3.1. The Concentrations of Compounds Used in the Biochemical and Molecular Analyses Did Not Show Signs of Toxicity. LPS treatment $(100 \mathrm{ng} / \mathrm{mL})$ resulted in an increase in $\mathrm{LDH}$ release in primary microglial cultures (Figure 1). Pretreatment with 2.0 $\mu \mathrm{M}$ AEA resulted in additional cytotoxicity, which was not present after pretreatment with $1.0 \mu \mathrm{M}$ AEA, so this concentration was chosen for use in subsequent experiments. None of the concentrations of AM-630 tested showed cytotoxicity in the LDH assay when administered with LPS; thus, $0.5 \mu \mathrm{M}$ was chosen for the biochemical and molecular analyses. AM-251 and CID-16020046 resulted in increased release of LDH when administered with LPS at the highest concentration; therefore, $0.25 \mu \mathrm{M}$, the highest nontoxic dose, was used for both compounds in subsequent experiments (Figure 1). None of the compounds used showed signs of cytotoxicity when administered without LPS (only the data for the highest dose is shown).

3.2. Involvement of Cannabinoid and GPR Receptors in the AEA-Mediated Alleviation of NO Production. An increase in the secretion of nitric oxide (NO) was observed $(312.50 \pm$ $7.81 \%$ of nonstimulated control, Figure 2) $24 \mathrm{~h}$ after the administration of LPS $(100 \mathrm{ng} / \mathrm{mL})$. AEA $(1 \mu \mathrm{M})$ administered 30 min prior to LPS stimulation reduced NO production by approximately $30 \%$ ( $215.55 \pm 8.84 \%$ of nonstimulated control, Figure 2). To determine the involvement of the respective receptors in the AEA-mediated effect, coadministration with AM-630 $(0.5 \mu \mathrm{M}), \mathrm{AM}-251(0.25 \mu \mathrm{M})$, and CID-16020046 $(0.25 \mu \mathrm{M})$ was performed in LPS-stimulated cells. Pretreatment with AM-630 compensated for the effect of AEA by approximately $40 \%$ compared to NO release in AEA- and LPS-treated cells (270.14 $\pm 9.77 \%$ of nonstimulated control, Figure 2). Antagonism of CB1 or GPR18/GPR55 did not change the level of released NO in AEA- and LPS-treated cells. Treatment with AM-630 and AM-251 alone did not significantly diminish NO production compared to the LPSstimulated control. 


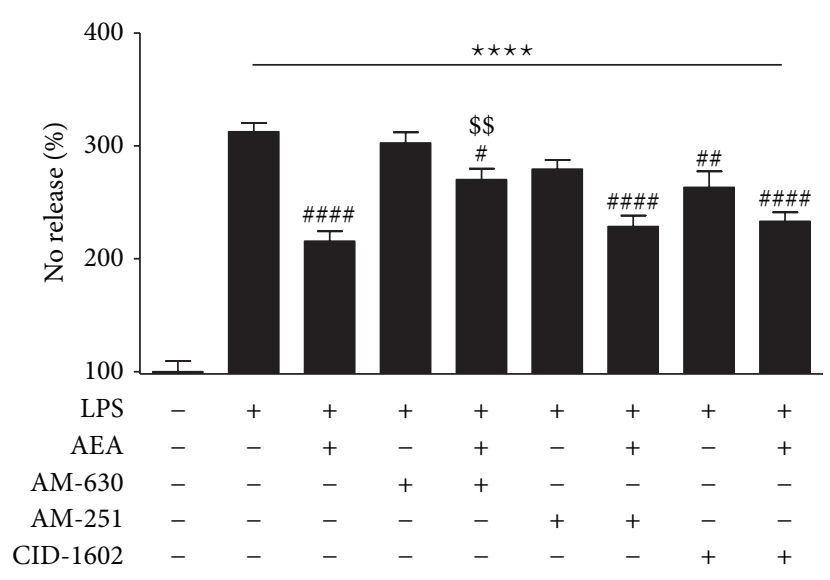

FIGURE 2: Release of nitric oxide in cultured rat primary microglia after LPS stimulation and pretreatment with AEA and AM-630, AM-251, or CID-16020046. The results are expressed as the percentage of NO release relative to the nonstimulated control (100\%), 24 hours after LPS stimulation. Data are presented as the mean \pm SEM and represent the normalized averages derived from 10 to 15 samples per group. Statistical analysis was performed using oneway ANOVA followed by Bonferroni post hoc tests. Statistical $P$ values $<0.05$ were considered significant. ${ }^{*}$ It denotes a significant difference versus the nonstimulated control; \#, versus the LPSstimulated control; \$, versus the LPS-stimulated cells treated with AEA.

3.3. Alteration of Cb1, Cb2, Gpr18, and Gpr55 Expression in LPS-Stimulated Primary Microglial Cells after Treatment with the Tested Compounds. CB1, CB2, GPR18, and GPR55 transcripts were detected in both nonstimulated and LPSstimulated primary microglial cell cultures. LPS stimulation significantly decreased the level of CB1 mRNA regardless of the compound used for treatment (Figure 3(a)). Significant upregulation of $\mathrm{Cb} 2$ expression was observed after AM-630 treatment in LPS-stimulated cells. Moreover, CB2 transcript levels tended to increase after AEA and CID16020046 treatment, although the changes were not significant (Figure 3(b)). LPS stimulation increased expression levels of Gpr18 in all treatments, with the highest expression in AM630-induced cells (Figure 3(c)). However, although no alteration of Gpr55 in LPS-stimulated cells was observed, pretreatment with AM-630, AM-251, or CID-16020046 resulted in elevated expression of this receptor transcript (Figure 3(d)).

\subsection{Expression of M1 Phenotype-Related Molecules in Rat} Primary Microglial Cultures after Treatment with LPS and the Tested Compounds. All of the tested proinflammatory factors showed significant upregulation after LPS stimulation. Il-1 $\beta$ showed an upward trend after AM-630 administration, although the change was not statistically significant (Figure 4(a)). Il-18 expression tended to decrease after AEA treatment, although the change was not significant. AM630 treatment resulted in significant upregulation of Il-18 expression (Figure 4(b)). Tnf- $\alpha$ expression tended to increase after LPS stimulation, although the increase was significant only after AM-630 treatment (Figure 4(c)). Upregulation of
IL-6 mRNA in LPS-stimulated cells was attenuated after AEA treatment. Administration of AM-251 showed similar effects on the decrease in IL-6 mRNA levels, and CID16020046 showed an even greater effect (Figure 4(d)). In contrast, AM-630 treatment produced no effect on the LPS-induced increase in IL-6 transcript. Both Cox2 and Nos2 showed patterns of mRNA expression similar to that of $\mathrm{Il}-6$ after treatment with the tested compounds in LPS-stimulated cell cultures (Figures 4(e) and 4(f)). Il-6 showed lower expression levels in LPS-stimulated cultures treated with AEA compared to LPS-stimulation alone. After AM-630 administration, the expression level of Il-6 returned to that of LPS-treated cells.

3.5. Changes in M2 Phenotype-Related Molecules in LPSStimulated Rat Primary Microglia after Treatment with the Tested Compounds. Expression of anti-inflammatory IL-10 mRNA was significantly elevated after AEA treatment in LPSstimulated cells (Figure 5(a)). Moreover, administration of AM-251 also showed similar results. After LPS stimulation, the expression of $\mathrm{Ng} f$ was significantly decreased. AM-630 and CID-16020046 did not alter NGF transcript levels in LPS-stimulated cell cultures (Figure 5(b)). In contrast, after treatment with AEA or AM-251, levels of NGF mRNA returned to the level of the nonstimulated control. Expression of IL-4 and IL-13 mRNA was below the detection level in both nonstimulated and LPS-stimulated primary microglial cell cultures.

\section{Discussion}

In the present study, we have demonstrated that the alleviating effect of AEA on NO production in primary microglial cultures is mediated mainly through CB2 receptors. Activated upon CNS damage, microglia initiate and play a critical role in the development of CNS inflammation. Various stimuli can activate microglia, causing proinflammatory or anti-inflammatory functions depending on the duration, nature, and scale of the stimulus [34]. It has been shown that the inflammatory response of LPS-stimulated microglia, which leads to increased secretion of $\mathrm{NO}$, contributes to events underlying brain inflammation and neuronal degeneration [35]. Biochemical studies performed on LPS-treated microglia have demonstrated similarity in the transcriptional activation of a large panel of inflammatory genes, including IL-1 $\beta$, IL-6, and IL-18 [36], which are typical of the M1 phenotype of activated microglia.

Some studies have indicated that short-term cannabinoid exposure can have a neuroprotective effect at the time of the sudden failure of CNS tissues [37]. Bursts of AEA, which is synthesized "on demand" in areas of cellular stress (e.g., in damaged tissue or at the site of inflammation), have been suggested as the mechanism that inhibits the immune response in both normal and injured tissues, where it is involved in the migration of immune cells to the site of inflammation [38]. Our study demonstrated a reduction in NO release after pretreatment with AEA in LPS-stimulated primary microglial cultures, which suggests it has a neuroprotective action during CNS tissue damage. The decrease in 


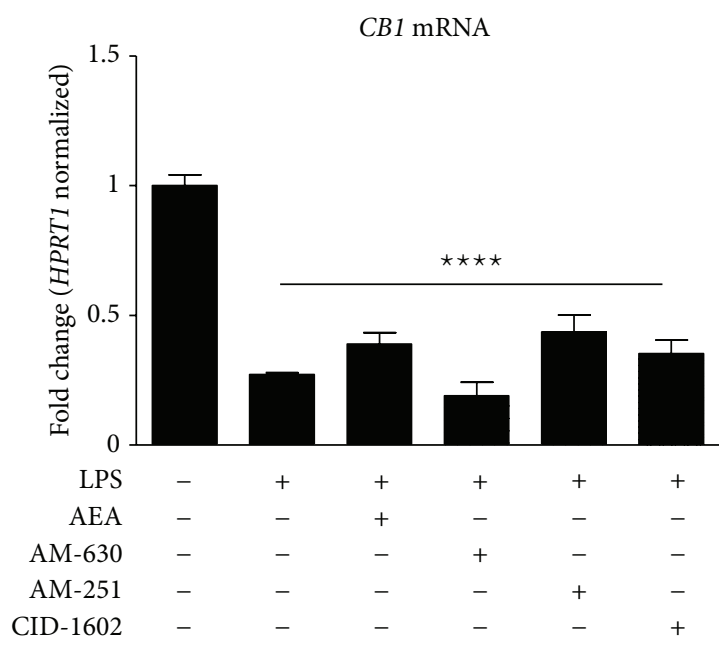

(a)

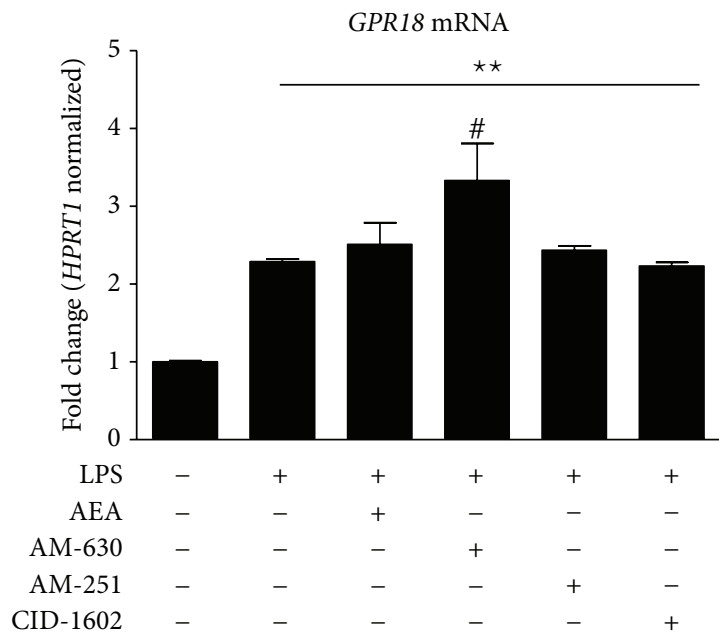

(c)

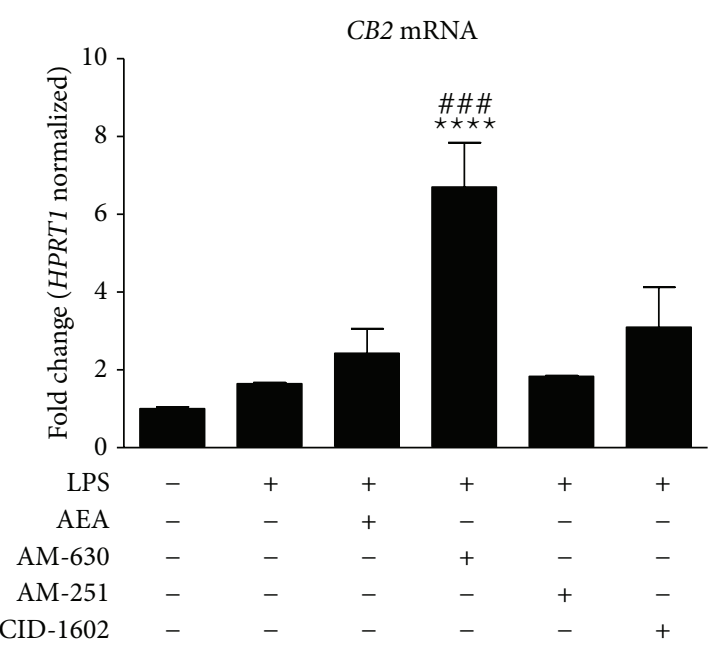

(b)

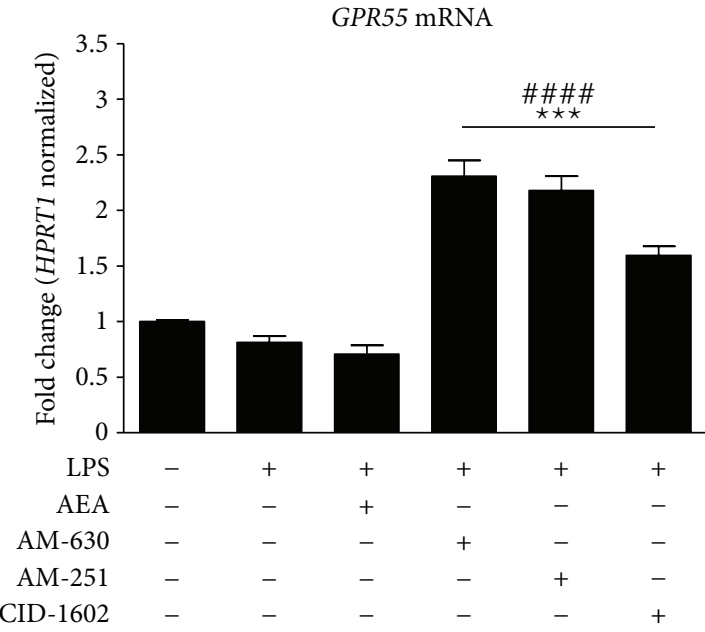

(d)

FIGURE 3: Expression of CB1, CB2, GPR55, and GPR18 transcripts in rat primary microglial cultures in the presence of the tested compounds. Samples were analyzed 24 hours after the stimulation of cells with LPS. Data are presented as the mean \pm SEM and represent the normalized averages derived from 6 to 8 samples per group. The results are presented as the fold-change normalized to the expression of the reference gene Hprtl and were calculated relative to nonstimulated cells. Statistical analysis was performed using one-way ANOVA followed by Bonferroni post hoc tests; $P$ values $<0.05$ were considered significant. ${ }^{\star}$ It denotes a significant difference versus the nonstimulated control; \#, versus the LPS-stimulated control.

NO production was correlated with a downregulation of Nos2 expression, in the absence of AEA toxicity in the LDH assay. Thus, it can be concluded that the reduction of NO production was not due to the toxicity of the AEA but to inhibition of the inducible NO synthase. Although it has been previously suggested that CB1 is expressed constitutively [39], our study showed a decrease in the expression of the CB1 receptor upon microglial activation, which may prove their contribution in response to LPS treatment. Interestingly pretreatment with none of used compound influenced $C b 1$ expression levels. However, it is difficult to clarify the involvement of CB1 in the inflammatory response, as both its agonists and antagonists demonstrate immunomodulatory functions [40].

We demonstrated that $\mathrm{Cb} 2$ expression tended to increase after LPS stimulation, although only additional treatment with AM-630 elevated the CB2 transcript level significantly. This result supports the finding that $C b 2$ expression is inducible upon inflammation [39]. Indeed, studies have shown that $\mathrm{CB} 2$ receptor activation reduces the immune response during CNS inflammation, brain edema, and the death of neurons, alleviating the symptoms of neurodegenerative diseases in animal models [41]. CB2 receptor stimulation inhibits the activation of microglia, slowing down the development of Alzheimer's disease [30]. Similarly, CB2 receptor activation in microglial cells in the spinal cord can reduce inflammatory reactions and pain after peripheral nerve injury [42-44]. Evidence of the modulation of CB2 expression after microglial activation is mixed. Some studies have shown that there is downregulation of $\mathrm{CB} 2$ receptor levels after activation [45], while others have reported that 


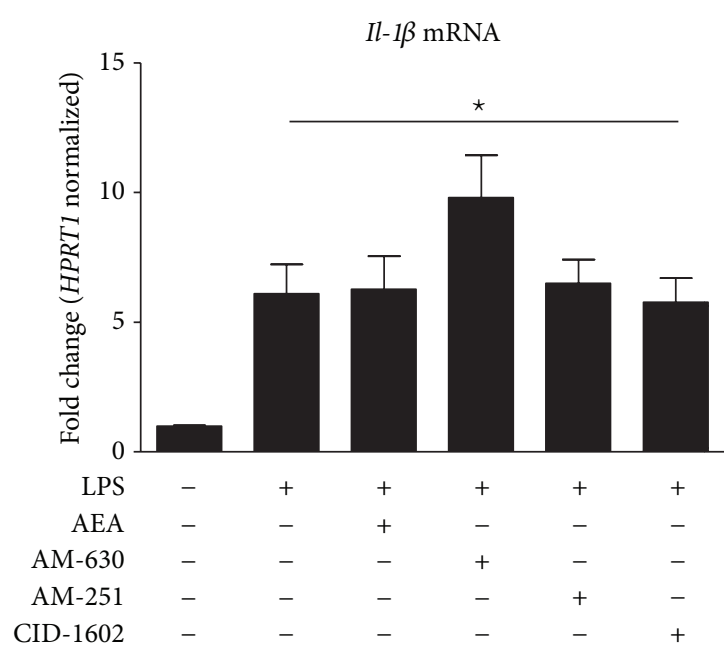

(a)

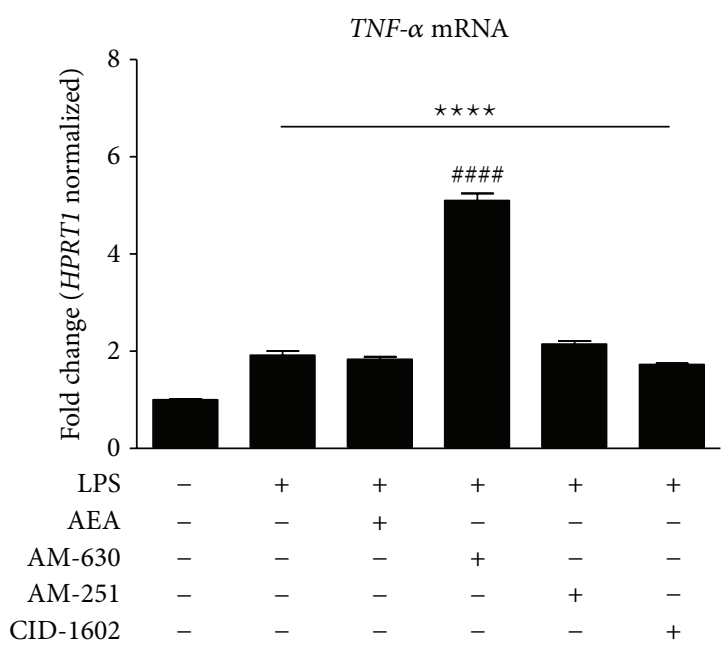

(c)

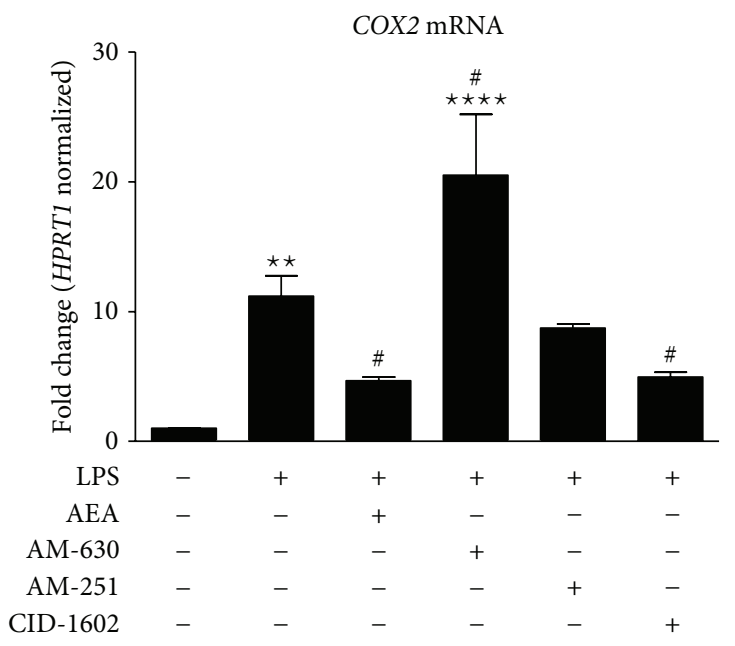

(e)

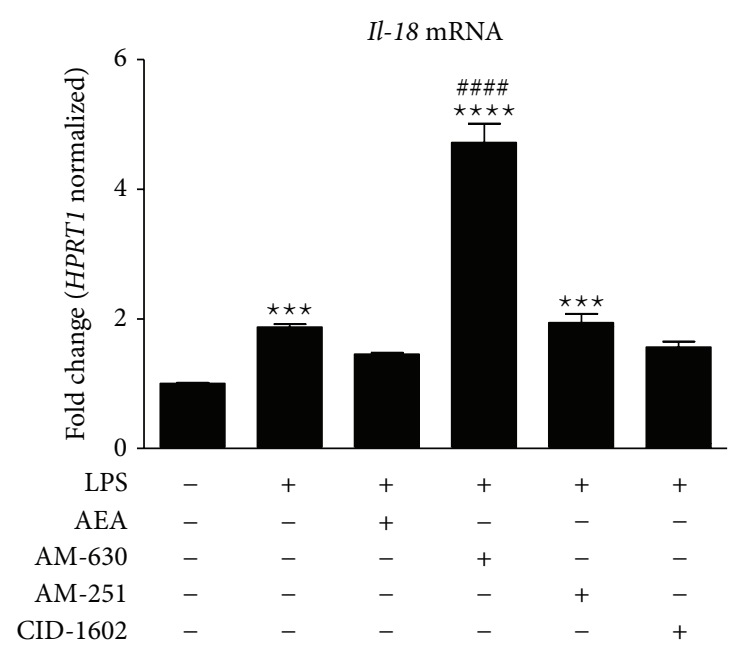

(b)

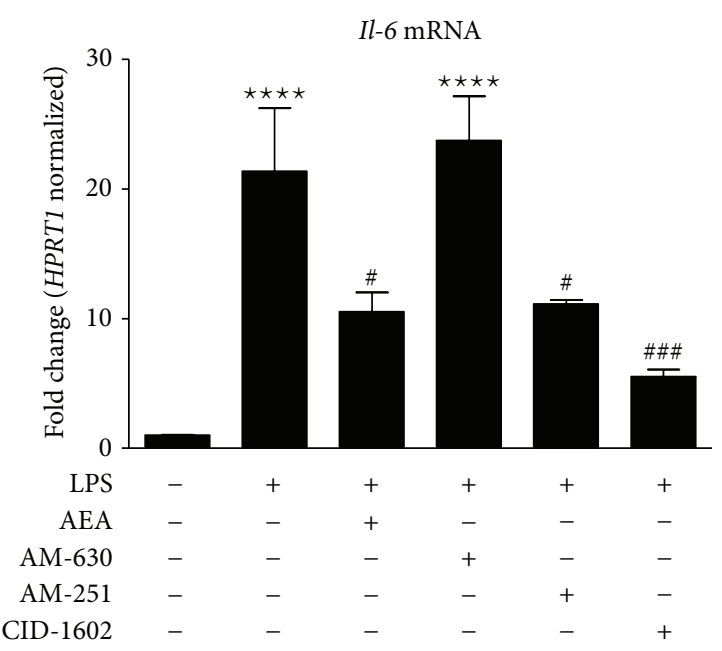

(d)

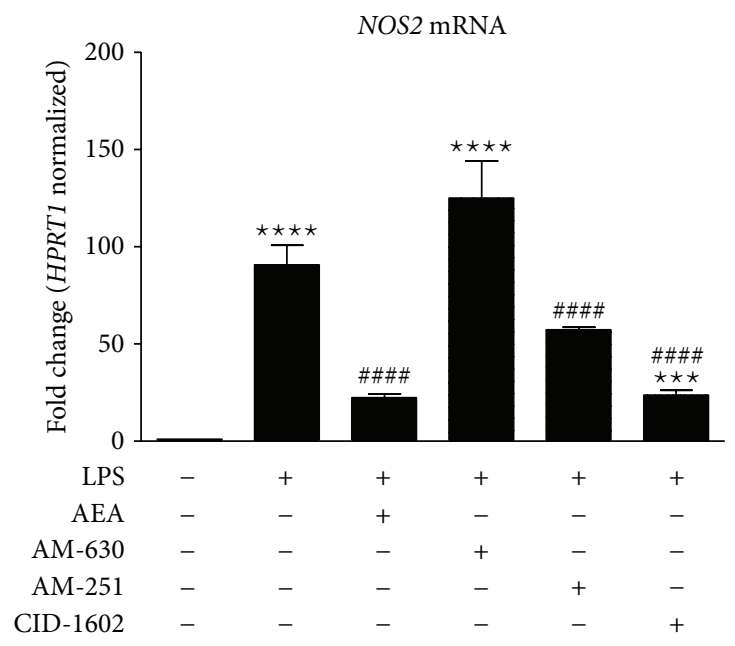

(f)

FIGURE 4: The results of qPCR analysis of the M1 phenotypic markers Tnf- $\alpha$, Ill $\beta$, Ill1, Il6, Cox2, and Nos2 gene expression in rat primary microglial cultures in the presence of the tested compounds. Samples were analyzed 24 hours after LPS stimulation. Data are presented as the mean \pm SEM and represent the normalized averages derived from 6 to 8 samples per group. The results are presented as fold-change normalized to the expression of the reference gene Hprt1 and were calculated relative to nonstimulated cells. Statistical analysis was performed using one-way ANOVA followed by Bonferroni post hoc tests; $P$ values $<0.05$ were considered significant. ${ }^{*}$ It denotes a significant difference versus the nonstimulated control; \#, versus the LPS-stimulated control. 


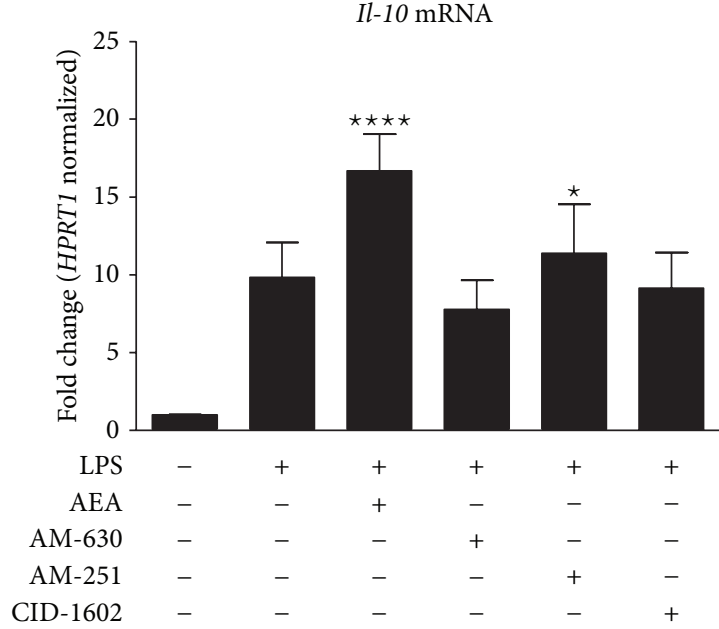

(a)

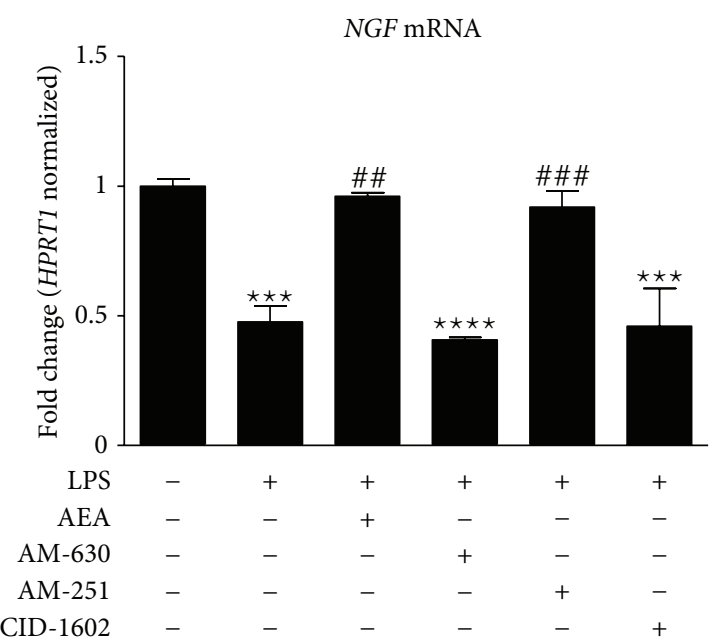

(b)

FiguRE 5: Expression of transcripts for the M2 phenotypic markers Il-10 and $N g f$ in rat primary microglial cultures in the presence of the tested compounds. Samples were analyzed 24 hours after the stimulation of cells with LPS. Data are presented as the mean \pm SEM and represent the normalized averages derived from 6 to 8 samples per group. The results are presented as fold-change normalized to the expression of the reference gene Hprtl and were calculated relative to nonstimulated cells. Statistical analysis was performed using one-way ANOVA followed by Bonferroni post hoc tests; values with $P<0.05$ were considered significant. ${ }^{*}$ It denotes a significant difference versus the nonstimulated control; \#, versus the LPS-stimulated control.

inflammatory stimuli upregulate CB2 microglial expression $[46,47]$.

Microglial activation is a polarized process that can be divided into M1 and M2 phenotypes [11, 48]. During the short-term activation of microglia, the presence of both the $\mathrm{M} 1$ and M2 phenotypes is balanced, allowing the restoration of CNS homeostasis; however, chronic inflammation causes a shift toward the proinflammatory M1 phenotype. One of the actions of activated microglia is the promotion of inflammation, which causes an influx of immune cells to the site of injury. To this end, the M1 phenotype of microglial cells initiates neuroinflammation by producing cytotoxic factors such as cytokines (e.g., IL-1 $\beta$, IL-6, IL-18, and TNF$\alpha$ ) and enzymes (NOS2 and COX2), which, in addition to acting as chemoattractants, may lead to neuronal damage upon chronic activation [49]. In our previous work [13], we reported that LPS-treated cells are an important source of many proinflammatory (e.g., IL-1 $\beta$, IL-6, and IL-18) and anti-inflammatory (e.g., IL-1 $\alpha$ and IL-10) factors. Moreover, cannabinoids can modulate cytokine production [50], which in turn contributes to a reduction of the immune response and can be beneficial in autoimmune diseases. It has been shown that the high levels of AEA observed during CNS damage are responsible for its neuroprotective effects, affecting the TLR4-dependent activation of microglia [51]. Modulation of intracellular signal transduction pathways leads to changes in the expression of immune response-related genes.

IL-1B, a marker of the microglial M1 phenotype, showed an elevated expression level after LPS treatment, which may suggest microglial polarization upon LPS activation. Similarly $\mathrm{Il}-18$ expression was also increased, which is consistent with studies in murine microglial cells [52]. Additional M1 phenotypic molecules, Il-6 and Cox2, showed upregulated expression in LPS-treated cells, which was alleviated by pretreatment with AEA, suggesting an anti-inflammatory action in LPS-stimulated primary microglial cultures. Moreover, decreased expression of Cox 2 may contribute to increased activation of the FAAH- and LOX-dependent metabolic pathways of AEA, which result in anti-inflammatory metabolites [53]. Tnf- $\alpha$, besides being upregulated upon LPS stimulation, showed elevated levels after AM-630 treatment. This result is consistent with studies showing suppression of Tnf$\alpha$ expression associated with reduced NO production in microglial cells after treatment with the CB2 receptor agonist [46]. Moreover, it has been reported that stimulation of CB2 receptors causes a reduction in the release of proinflammatory cytokines, such as TNF- $\alpha$ and IL-6 [54].

During short-term activation of microglia, a balanced immune response is maintained by anti-inflammatory factors (e.g., IL-4, IL-13, IL-10, and NGF) produced by cells with the M2-phenotype, which allows the management of CNS inflammation [55]. In our studies, $\mathrm{Il}-10$ levels were significantly increased after AEA treatment. As IL-10 inhibits the release of IL- $1 \beta$ and IL- 6 , it may play an important role in the development of neuroinflammation [56]. NGF has a welldocumented neuroprotective effect (for review see [57]) and is a specific marker of M2-phenotype microglia [12, 17]. Our study showed downregulation of $\mathrm{Ng} f$ expression after LPS stimulation, which was restored to baseline levels with AEA treatment.

We reported that AEA alleviation of NO production was not abolished by CB1 antagonism, although it was sensitive to CB2 antagonism. AM-630 partially blocked the AEA effect on NO production, together with the elevated expression of 
Nos2 in LPS-induced primary microglial cultures. It has been shown that AEA inhibits NO release and Nos2! expression in an LPS-activated murine microglial cell line (BV2-cells). This effect is sensitive to CB2 but not CB1 antagonism, as indicated by the finding that neuronal death was even greater after AM-630, but not AM-251, administration [38]. Our findings, together with these results, strongly suggest that the endocannabinoid system, and in particular CB2 receptors, is involved in the regulation of neuroinflammation. Incomplete attenuation of the AEA effect by the CB2 antagonist may be due to the action of AEA on other molecular targets. $\mathrm{CB} 1$ and $\mathrm{CB} 2$ are well-documented targets of AEA, but there is also evidence of the activation of other receptors by this compound. Studies by Puffenbarger et al. [58] have demonstrated reduced levels of Il-1 $\beta, I l-6$, and Tnf- $\alpha$ expression after cannabinoid administration in activated microglial cells, which is not sensitive to $\mathrm{CB} 1$ and $\mathrm{CB} 2$, suggesting the presence of an additional, as yet unidentified, cannabinoid receptor on microglia. Among the numerous candidates of particular interest are GPR18 and GPR55, which have been shown to be involved in the immunomodulatory effects, and the expression of which has been demonstrated on microglial cells [21, 59-61].

Interaction between GPR55 and CB2 in the control of inflammatory processes has been reported $[22,62,63]$. Although the expression of Gpr55 was not elevated after LPS induction, pretreatment with AM-251, AM-630, or CID16020046 resulted in a significant increase in GPR55 mRNA levels. These results support its hypothesized function in dampening excessive cannabinoid receptor activation [64]. Moreover, administration of AM-630 caused an increase in Gpr18 expression, which may further suggest functional cross talk between CB2 and GPR18 receptors. Interestingly, recent findings have suggested that GPR18 may act as a new microglial target in the control of neuroimmunological episodes in the CNS (for review see [61]). Our data indicates Gpr18 expression is elevated after LPS induction, regardless of the compound used for treatment.

Although CID-16020046, a mixed antagonist of GPR18/ GPR55, did not block the effect of AEA on NO production in primary microglial cultures in our studies, it decreased NO release when administered alone. The abolishment of NO production by antagonism of GPR18/GPR55 suggests that they may play a role as immune modulators. Because of the lack of selective pharmacological tools at this time, further studies using knockouts are needed to confirm this hypothesis.

Our studies showed that AEA causes a reduction in microglial cell activation, especially by dampening activation of the M1 phenotype. We demonstrated the involvement of the CB2 receptor in the cytoprotective effect of AEA. Moreover, we provided novel, interesting data of the involvement of GPR18/GPR55 in microglial activation. Summing up, the use of pharmacological tools to control the phenotype of microglia through the endocannabinoid system may be useful in the treatment of neurodegenerative conditions.

\author{
Abbreviations

$\begin{array}{ll}\text { AEA: } & \text { Anandamide } \\ \text { AM-251: } & \text { CB1 receptor antagonist } \\ \text { AM-630: } & \text { CB2 receptor antagonist } \\ \text { CB1: } & \text { Cannabinoid receptor type 1 } \\ \text { CB2: } & \text { Cannabinoid receptor type 2 } \\ \text { CID-16020046: } & \text { GPR18/GPR55 receptors antagonist } \\ \text { COX2: } & \text { Cyclooxygenase 2 } \\ \text { CNS: } & \text { Central nervous system } \\ \text { FAAH: } & \text { Fatty acid amide hydrolase } \\ \text { GPR18/GPR55: } & \text { G-coupled protein receptor 18/55 } \\ \text { HPRT1: } & \text { Hypoxanthine-guanine } \\ & \text { phosphoribosyltransferase 1 } \\ \text { IL-1 }:: & \text { Interleukin-1 } \beta \\ \text { IL-4: } & \text { Interleukin-4 } \\ \text { IL-6: } & \text { Interleukin-6 } \\ I L-10: & \text { Interleukin-10 } \\ I L-13: & \text { Interleukin-13 } \\ I L-18: & \text { Interleukin-18 } \\ L D H: & \text { Lactate dehydrogenase } \\ L O X: & \text { Lipoxygenase } \\ L P S: & \text { Lipopolysaccharide } \\ N G F: & \text { Nerve growth factor } \\ N O: & \text { Nitric oxide (II) } \\ N O S 2: & \text { Nitric oxide synthase 2 } \\ \text { TLR-4: } & \text { Toll-like receptor-4 } \\ \text { TNF- } \alpha: & \text { Tumor necrosis factor- } \alpha \\ \text { TRPV1: } & \text { Transient receptor potential cation } \\ & \text { channel subfamily V member 1. } \\ & \end{array}$

\section{Conflict of Interests}

The authors declare that they have no competing interests.

\section{Authors' Contribution}

Natalia Malek was responsible for experimental design, acquisition of biochemical and molecular data, analysis and interpretation of data, and writing of the paper. Katarzyna Popiolek-Barczyk was responsible for primary microglia culture preparation, analysis and interpretation of data, and writing of the paper. Joanna Mika was responsible for analysis and interpretation of data and writing of the paper. Barbara Przewlocka was responsible for analysis and interpretation of data and writing of the paper. Katarzyna Starowicz was responsible for study conception, experimental design, analysis and interpretation of data, and writing of paper. All authors read and approved the final paper.

\section{Acknowledgments}

This work was supported by the National Science Centre, Poland, Grant SONATA BIS NCN/2012/07/E/NZ7/01269, OPUS NCN/2011/03/B/NZ4/00042, and statutory funds. Natalia Malek and Katarzyna Popiolek-Barczyk are recipients of a scholarship from KNOW sponsored by the Ministry of Science and Higher Education, Republic of Poland 


\section{References}

[1] M. Song, J. Jin, J.-E. Lim et al., "TLR4 mutation reduces microglial activation, increases $\mathrm{A} \beta$ deposits and exacerbates cognitive deficits in a mouse model of Alzheimer's disease," Journal of Neuroinflammation, vol. 8, article 92, 2011.

[2] C. M. R. Barcia, "IFN- $\gamma$ signaling, with the synergistic contribution of TNF- $\alpha$, mediates cell specific microglial and astroglial activation in experimental models of Parkinson's disease," Cell Death \& Disease, vol. 2, p. e142, 2011.

[3] S. H. Appel, W. Zhao, D. R. Beers, and J. S. Henkel, "The microglial-motoneuron dialogue in ALS," Acta Myologica, vol. 30, no. 1, pp. 4-8, 2011.

[4] A. Y. Lai and K. G. Todd, "Microglia in cerebral ischemia: molecular actions and interactions," Canadian Journal of Physiology and Pharmacology, vol. 84, no. 1, pp. 49-59, 2006.

[5] J. Mika, M. Osikowicz, E. Rojewska et al., "Differential activation of spinal microglial and astroglial cells in a mouse model of peripheral neuropathic pain," European Journal of Pharmacology, vol. 623, no. 1-3, pp. 65-72, 2009.

[6] M. L. Loggia, D. B. Chonde, O. Akeju et al., "Evidence for brain glial activation in chronic pain patients," Brain, vol. 138, part 3, pp. 604-615, 2015.

[7] A. O. Caggiano, C. D. Breder, and R. P. Kraig, "Long-term elevation of cyclooxygenase-2, but not lipoxygenase, in regions synaptically distant from spreading depression," Journal of Comparative Neurology, vol. 376, no. 3, pp. 447-462, 1996.

[8] C. J. Hauser, "Regional macrophage activation after injury and the compartmentalization of inflammation in trauma," New Horizons, vol. 4, no. 2, pp. 235-251, 1996.

[9] J. E. Merrill and E. N. Benveniste, "Cytokines in inflammatory brain lesions: helpful and harmful," Trends in Neurosciences, vol. 19, no. 8, pp. 331-338, 1996.

[10] C. Cunningham, "Microglia and neurodegeneration: the role of systemic inflammation," Glia, vol. 61, no. 1, pp. 71-90, 2013.

[11] J. M. Crain, M. Nikodemova, and J. J. Watters, "Microglia express distinct M1 and M2 phenotypic markers in the postnatal and adult central nervous system in male and female mice," Journal of Neuroscience Research, vol. 91, no. 9, pp. 1143-1151, 2013.

[12] X. Hu, P. Li, Y. Guo et al., "Microglia/macrophage polarization dynamics reveal novel mechanism of injury expansion after focal cerebral ischemia," Stroke, vol. 43, no. 11, pp. 3063-3070, 2012.

[13] E. Rojewska, K. Popiolek-Barczyk, A. M. Jurga, W. Makuch, B. Przewlocka, and J. Mika, "Involvement of pro- and antinociceptive factors in minocycline analgesia in rat neuropathic pain model," Journal of Neuroimmunology, vol. 277, no. 1-2, pp. 57-66, 2014.

[14] W. Y. Tam and C. H. E. Ma, "Bipolar/rod-shaped microglia are proliferating microglia with distinct M1/M2 phenotypes," Scientific Reports, vol. 4, article 7279, 2014.

[15] Y. Nishio, M. Koda, M. Hashimoto et al., "Deletion of macrophage migration inhibitory factor attenuates neuronal death and promotes functional recovery after compressioninduced spinal cord injury in mice," Acta Neuropathologica, vol. 117, no. 3, pp. 321-328, 2009.

[16] P. G. Popovich, Z. Guan, P. Wei, I. Huitinga, N. van Rooijen, and B. T. Stokes, "Depletion of hematogenous macrophages promotes partial hindlimb recovery and neuroanatomical repair after experimental spinal cord injury," Experimental Neurology, vol. 158 , no. 2, pp. 351-365, 1999.
[17] B. Koscsó, B. Csóka, E. Kókai et al., "Adenosine augments IL10 -induced STAT3 signaling in M2c macrophages," Journal of Leukocyte Biology, vol. 94, no. 6, pp. 1309-1315, 2013.

[18] S. Poole, F. Q. Cunha, S. Selkirk, B. B. Lorenzetti, and S. H. Ferreira, "Cytokine-mediated inflammatory hyperalgesia limited by interleukin-10," British Journal of Pharmacology, vol. 115, no. 4, pp. 684-688, 1995.

[19] Y. Marchalant, S. Rosi, and G. L. Wenk, "Anti-inflammatory property of the cannabinoid agonist WIN-55212-2 in a rodent model of chronic brain inflammation," Neuroscience, vol. 144, no. 4, pp. 1516-1522, 2007.

[20] M. Van der Stelt and V. Di Marzo, "Cannabinoid receptors and their role in neuroprotection," NeuroMolecular Medicine, vol. 7, no. 1-2, pp. 37-50, 2005.

[21] C. Andradas, M. M. Caffarel, E. Pérez-Gómez et al., "The orphan G protein-coupled receptor GPR55 promotes cancer cell proliferation via ERK," Oncogene, vol. 30, no. 2, pp. 245-252, 2011.

[22] N. A. B. Balenga, C. M. Henstridge, J. Kargl, and M. Waldhoer, "Pharmacology, signaling and physiological relevance of the G protein-coupled receptor 55," Advances in Pharmacology, vol. 62, pp. 251-277, 2011.

[23] A. G. Hohmann, R. L. Suplita, N. M. Bolton et al., "An endocannabinoid mechanism for stress-induced analgesia," Nature, vol. 435, no. 7045, pp. 1108-1112, 2005.

[24] G. A. Cabral, K. N. Harmon, and S. J. Carlisle, "Cannabinoidmediated inhibition of inducible nitric oxide production by rat microglial cells: Evidence for cbl receptor participation," Advances in Experimental Medicine and Biology, vol. 493, pp. 207-214, 2001.

[25] D. Sinha, T. I. Bonner, N. R. Bhat, and L. A. Matsuda, "Expression of the CB1 cannabinoid receptor in macrophagelike cells from brain tissue: immunochemical characterization by fusion protein antibodies," Journal of Neuroimmunology, vol. 82, no. 1, pp. 13-21, 1998.

[26] L. Walter, A. Franklin, A. Witting, T. Möller, and N. Stella, "Astrocytes in culture produce anandamide and other acylethanolamides," The Journal of Biological Chemistry, vol. 277, no. 23, pp. 20869-20876, 2002.

[27] Y. Liu, W. Hao, M. Letiembre et al., "Suppression of microglial inflammatory activity by myelin phagocytosis: role of p47PHOX-mediated generation of reactive oxygen species," The Journal of Neuroscience, vol. 26, no. 50, pp. 12904-12913, 2006.

[28] D. Baker, G. Pryce, J. L. Croxford et al., "Endocannabinoids control spasticity in a multiple sclerosis model," The FASEB Journal, vol. 15, no. 2, pp. 300-302, 2001.

[29] C. Berger, P. C. Schmid, W.-R. Schabitz, M. Wolf, S. Schwab, and H. H. O. Schmidt, "Massive accumulation of $N$-acylethanolamines after stroke. Cell signalling in acute cerebral ischemia?" Journal of Neurochemistry, vol. 88, no. 5, pp. 1159-1167, 2004.

[30] B. G. Ramírez, C. Blázquez, T. Gómez Del Pulgar, M. Guzmán, and M. L. De Ceballos, "Prevention of Alzheimer's disease pathology by cannabinoids: neuroprotection mediated by blockade of microglial activation," Journal of Neuroscience, vol. 25, no. 8, pp. 1904-1913, 2005.

[31] M. Zawadzka and B. Kaminska, "A novel mechanism of FK506mediated neuroprotection: Downregulation of cytokine expression in glial cells," Glia, vol. 49, no. 1, pp. 36-51, 2005.

[32] K. Popiolek-Barczyk, E. Rojewska, A. M. Jurga et al., "Minocycline enhances the effectiveness of nociceptin/orphanin FQ during neuropathic pain," BioMed Research International, vol. 2014, Article ID 762930, 12 pages, 2014. 
[33] P. Chomczynski and N. Sacchi, "Single-step method of RNA isolation by acid guanidinium thiocyanate-phenol-chloroform extraction," Analytical Biochemistry, vol. 162, no. 1, pp. 156-159, 1987.

[34] M. Schwartz, O. Butovsky, and J. Kipnis, "Does inflammation in an autoimmune disease differ from inflammation in neurodegenerative diseases? Possible implications for therapy," Journal of Neuroimmune Pharmacology, vol. 1, no. 1, pp. 4-10, 2006.

[35] J. Gehrmann, Y. Matsumoto, and G. W. Kreutzberg, "Microglia: intrinsic immuneffector cell of the brain," Brain Research Reviews, vol. 20, no. 3, pp. 269-287, 1995.

[36] M. Zawadzka, M. Dabrowski, A. Gozdz et al., "Early steps of microglial activation are directly affected by neuroprotectant FK506 in both in vitro inflammation and in rat model of stroke," Journal of Molecular Medicine, vol. 90, no. 12, pp. 1459-1471, 2012.

[37] G. Marsicano, S. Goodenough, K. Monory et al., "CB1 cannabinoid receptors and on-demand defense against excitotoxicity," Science, vol. 302, no. 5642, pp. 84-88, 2003.

[38] E. Eljaschewitsch, A. Witting, C. Mawrin et al., "The endocannabinoid anandamide protects neurons during CNS inflammation by induction of MKP-1 in microglial cells," Neuron, vol. 49, no. 1, pp. 67-79, 2006.

[39] G. A. Cabral and F. Marciano-Cabral, "Cannabinoid receptors in microglia of the central nervous system: immune functional relevance," Journal of Leukocyte Biology, vol. 78, no. 6, pp. 11921197, 2005.

[40] M. Karsak, E. Gaffal, R. Date et al., "Attenuation of allergic contact dermatitis through the endocannabinoid system," Science, vol. 316, no. 5830, pp. 1494-1497, 2007.

[41] J. Palazuelos, T. Aguado, M. R. Pazos et al., "Microglial CB2 cannabinoid receptors are neuroprotective in Huntington's disease excitotoxicity," Brain, vol. 132, part 11, pp. 3152-3164, 2009.

[42] A. Romero-Sandoval, N. Nutile-Mcmenemy, and J. A. DeLeo, "Spinal microglial and perivascular cell cannabinoid receptor type 2 activation reduces behavioral hypersensitivity without tolerance after peripheral nerve injury," Anesthesiology, vol. 108, no. 4, pp. 722-734, 2008.

[43] L. Luongo, E. Palazzo, S. Tambaro et al., "1- $\left(2^{\prime}, 4^{\prime}\right.$-dichlorophenyl)-6-methyl-N-cyclohexylamine-1,4-dihy droindeno[1,2c]pyrazole-3-carboxamide, a novel CB2 agonist, alleviates neuropathic pain through functional microglial changes in mice," Neurobiology of Disease, vol. 37, no. 1, pp. 177-185, 2010.

[44] I. Racz, X. Nadal, J. Alferink et al., "Crucial role of CB2 cannabinoid receptor in the regulation of central immune responses during neuropathic pain," Journal of Neuroscience, vol. 28, no. 46, pp. 12125-12135, 2008.

[45] S. J. Carlisle, F. Marciano-Cabral, A. Staab, C. Ludwick, and G. A. Cabral, "Differential expression of the CB2 cannabinoid receptor by rodent macrophages and macrophage-like cells in relation to cell activation," International Immunopharmacology, vol. 2, no. 1, pp. 69-82, 2002.

[46] K. Maresz, E. J. Carrier, E. D. Ponomarev, C. J. Hillard, and B. N. Dittel, "Modulation of the cannabinoid $\mathrm{CB}_{2}$ receptor in microglial cells in response to inflammatory stimuli," Journal of Neurochemistry, vol. 95, no. 2, pp. 437-445, 2005.

[47] J. Ehrhart, D. Obregon, T. Mori et al., "Stimulation of cannabinoid receptor 2 (CB2) suppresses microglial activation," Journal of Neuroinflammation, vol. 2, article 29, 2005.

[48] K. A. Kigerl, J. C. Gensel, D. P. Ankeny, J. K. Alexander, D. J. Donnelly, and P. G. Popovich, "Identification of two distinct macrophage subsets with divergent effects causing either neurotoxicity or regeneration in the injured mouse spinal cord," The Journal of Neuroscience, vol. 29, no. 43, pp. 1343513444, 2009.

[49] R. Glass and M. Synowitz, "CNS macrophages and peripheral myeloid cells in brain tumours," Acta Neuropathologica, vol. 128, no. 3, pp. 347-362, 2014.

[50] T. W. Klein, C. A. Newton, N. Nakachi, and H. Friedman, "Delta 9-tetrahydrocannabinol treatment suppresses immunity and early IFN-gamma, IL-12, and IL-12 receptor beta 2 responses to Legionella pneumophila infection," The Journal of Immunology, vol. 164, no. 12, pp. 6461-6466, 2000.

[51] S. Rivest, "Cannabinoids in microglia: a new trick for immune surveillance and neuroprotection," Neuron, vol. 49, no. 1, pp. 4$8,2006$.

[52] M. Prinz and U.-K. Hanisch, "Murine microglial cells produce and respond to interleukin-18," Journal of Neurochemistry, vol. 72, no. 5, pp. 2215-2218, 1999.

[53] D. McHugh, S. S. J. Hu, N. Rimmerman et al., "N-arachidonoyl glycine, an abundant endogenous lipid, potently drives directed cellular migration through GPR18, the putative abnormal cannabidiol receptor," BMC Neuroscience, vol. 11, article no. 44, 2010.

[54] S. Chuchawankul, M. Shima, N. E. Buckley, C. B. Hartmann, and K. L. McCoy, "Role of cannabinoid receptors in inhibiting macrophage costimulatory activity," International Immunopharmacology, vol. 4, no. 2, pp. 265-278, 2004.

[55] O. Ullrich, K. Merker, J. Timm, and S. Tauber, "Immune control by endocannabinoids-new mechanisms of neuroprotection?" Journal of Neuroimmunology, vol. 184, no. 1-2, pp. 127-135, 2007.

[56] S. A. Kanaan, S. Poole, N. E. Saadé, S. Jabbur, and B. SafiehGarabedian, "Interleukin-10 reduces the endotoxin-induced hyperalgesia in mice," Journal of Neuroimmunology, vol. 86, no. 2, pp. 142-150, 1998.

[57] L. Aloe, M. L. Rocco, P. Bianchi, and L. Manni, "Nerve growth factor: from the early discoveries to the potential clinical use," Journal of Translational Medicine, vol. 10, no. 1, article 239, 2012.

[58] R. A. Puffenbarger, A. C. Boothe, and G. A. Cabral, "Cannabinoids inhibit LPS-inducible cytokine mRNA expression in rat microglial cells," Glia, vol. 29, no. 1, pp. 58-69, 2000.

[59] P. C. Staton, J. P. Hatcher, D. J. Walker et al., "The putative cannabinoid receptor GPR55 plays a role in mechanical hyperalgesia associated with inflammatory and neuropathic pain," Pain, vol. 139, no. 1, pp. 225-236, 2008.

[60] M. Pietr, E. Kozela, R. Levy et al., "Differential changes in GPR55 during microglial cell activation," FEBS Letters, vol. 583, no. 12, pp. 2071-2076, 2009.

[61] D. McHugh, "GPR18 in microglia: implications for the CNS and endocannabinoid system signalling," British Journal of Pharmacology, vol. 167, no. 8, pp. 1575-1582, 2012.

[62] N. A. Balenga, E. Martínez-Pinilla, J. Kargl et al., "Heteromerization of GPR55 and cannabinoid $\mathrm{CB}_{2}$ receptors modulates signalling," British Journal of Pharmacology, vol. 171, no. 23, pp. 5387-5406, 2014.

[63] N. A. B. Balenga, E. Aflaki, J. Kargl et al., "GPR55 regulates cannabinoid 2 receptor-mediated responses in human neutrophils," Cell Research, vol. 21, no. 10, pp. 1452-1469, 2011.

[64] E. Moreno, C. Andradas, M. Medrano et al., "Targeting CB2GPR55 receptor heteromers modulates cancer cell signaling," Journal of Biological Chemistry, vol. 289, no. 32, pp. 21960-21972, 2014. 

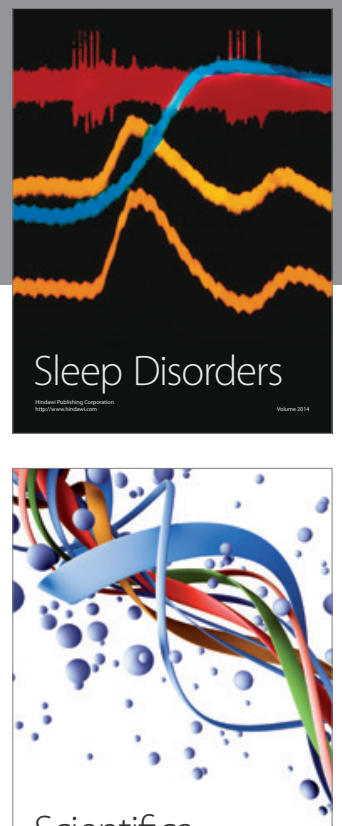

Scientifica
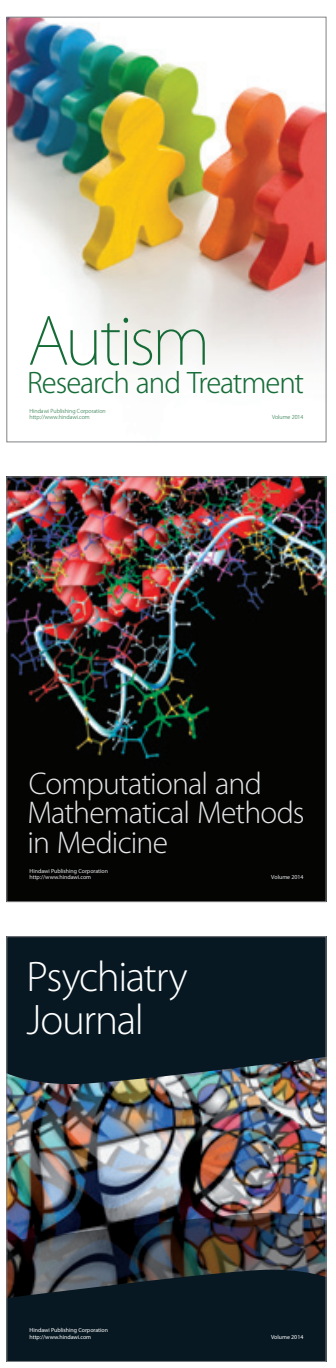
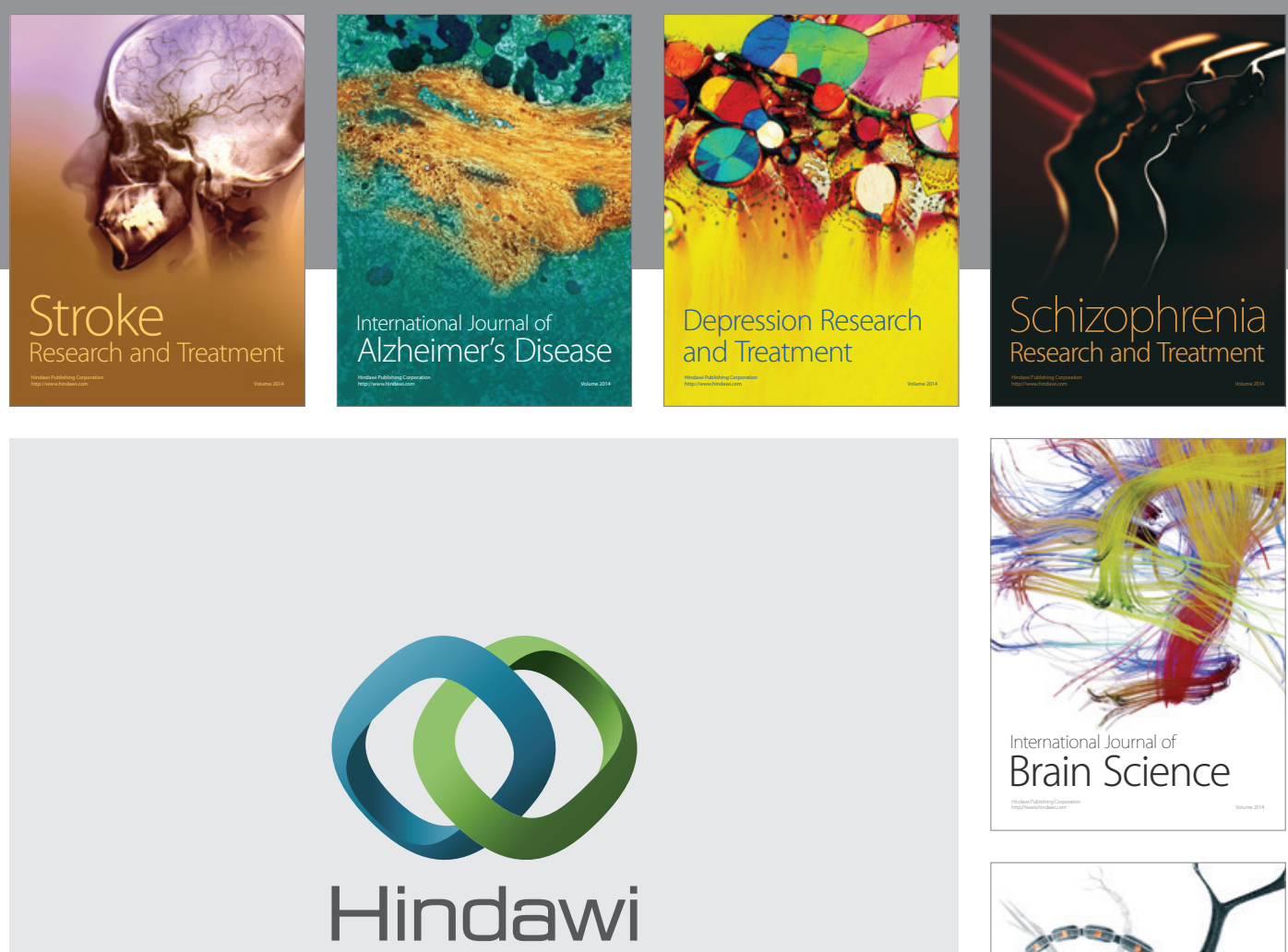

Submit your manuscripts at

http://www.hindawi.com
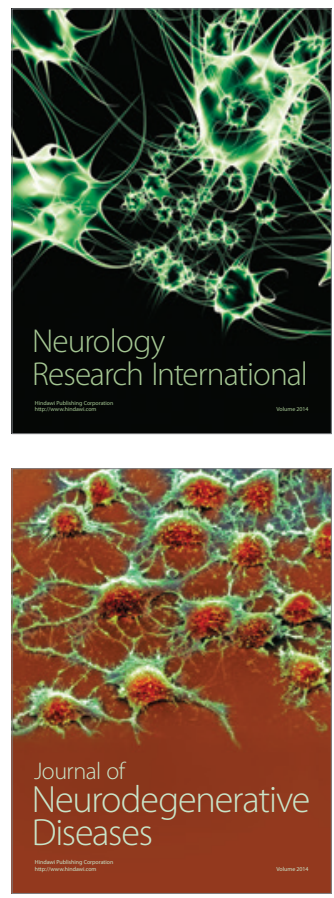

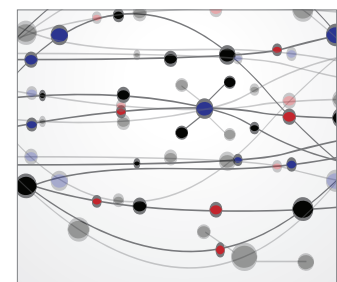

The Scientific World Journal
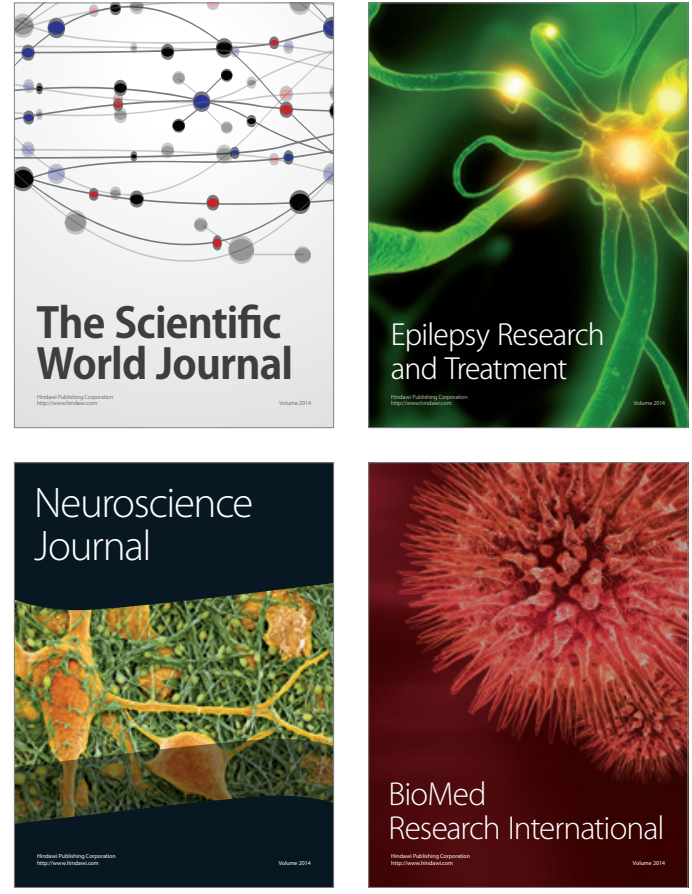

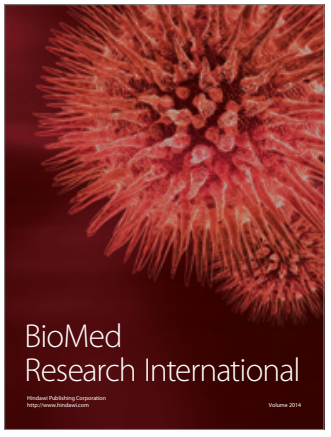

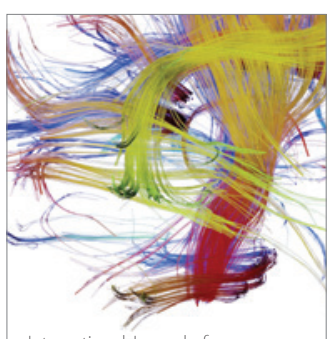

Brain Science

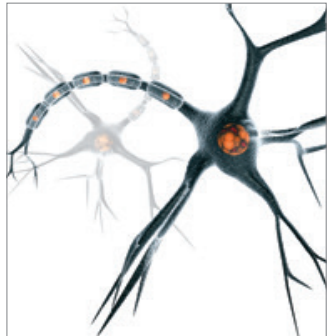

Neural Plasticity
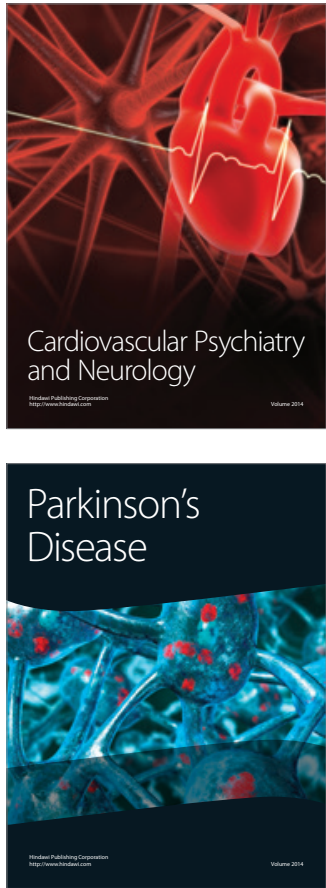